\title{
NEURAL NETWORK MODELING IN PROBLEMS OF ELECTRICAL GRIDS MODES PREDICTION
}

Purpose. Forming a neuro-fuzzy network based on temperature monitoring of overhead transmission line for the prediction modes of the electrical network. Methodology. To predict the load capacity of the overhead line architecture provides the use of neuro-fuzzy network based on temperature monitoring of overhead line. The proposed neuro-fuzzy network has a four-layer architecture with direct transmission of information. To create a full mesh network architecture based on hybrid neural elements with power estimation accuracy of the following two stages of the procedure: - in the first stage a core network (without power estimation accuracy) is generated; - in the second stage architecture and network parameters are fixed obtained during the first stage, and it is added to the block estimation accuracy, the input signals which are all input, internal and output signals of the core network, as well as additional input signals. Results. Formed neuro-fuzzy network based on temperature monitoring of overhead line. Originality. A distinctive feature of the proposed network is the ability to process information specified in the different scales of measurement, and high performance for prediction modes mains. Practical value. The monitoring system will become a tool parameter is measuring the temperature of the wire, which will, based on a retrospective analysis of the accumulated information on the parameters to predict the thermal resistance of the $H V$ line and as a result carry out the calculation of load capacity in real time. References 10, figures 1.

Key words: electric grid, neural grid, neuro-fuzzy grid, temperature monitoring of overhead transmission line, electric grid modes prediction.

В статье сформирована нейро-фаззи сеть с учетом температурного мониторинга воздуиной линии. Отличительной особенностью, предложенной сети, являются возможность обработки информации, заданной в разных шкалах измерения, и высокое быстродействие для прогнозирования режимов работы электрической сети. Библ. 10 , рис. 1 .

Ключевые слова: электрическая сеть, нейросеть, нейро-фаззи сеть, температурный мониторинг воздушной линии, прогнозирование режимов работы электрической сети.

Introduction. An important factor in the operation of electrical networks (EN), is an increase in load and the aging power grid equipment, which is typical for most industrialized countries. The capacity of the EN is reduced over time due to branching and complexity of network configuration. This fact increases the burden of overhead transmission lines (OL) as the backbone and distribution ones. The lack of information about the real parameters of the OL forces to use close to reality calculations of allowable power network modes. In most cases, they do not correspond to the actual operating conditions of networks, which leads to a significant reduction in transit overflows of power and overload of EN elements.

To eliminate unacceptable overload of EN elements measures of emergency control are provided. Devices of OL automatic overload limiting are designed for emergency control, which includes: EN configuration change, off of parts of the electricity consumers which reliability category allows a break of power supply, disconnect the OL.

The main requirement for such devices is the selectivity of action, i.e. automatic should only act at inadmissible modes of operation, without limiting the EN capacity. Prediction of the EN capacity is possible on the basis of real and stored information on its parameters.

Analysis of recent publications. As the analysis of the scientific information sources shown, the problems of predicting energy consumption are solved almost by all the institutions associated with the production and its distribution. To solve these problems traditional forecasting methods (regression, correlation, spectral analysis Box-Jenkins approach, exponential smoothing, adaptive predictors, etc.), as well as more advanced approaches based on data mining - Data Mining [1] are used.

The advantage of the traditional approaches is to ease the use of predictive models and the availability of affordable software. However, due to the fact that the link between energy consumption and its underlying causes are often complex and non-linear, in the framework of these approaches to achieve acceptable accuracy predictions is not always possible [2].

Significant difficulties in using computational intelligence systems occur when a part of the processed information is not given in the quantitative but ordinal or nominal scales. Already traditional neuro- and neurofuzzy networks are ill-suited to the kind of information processing «bad, normal, good weather», «strong or weak wind», «cloudy - foggy - frosty», etc. [3].

In connection with this the synthesis of a predictive neuro-fuzzy network able to perceive the data in different scales and its training algorithm, which has a high rate of convergence and the ability to process information as it becomes available in real time are proposed [4].

(C) A.N. Moroz, N.M. Cheremisin, V.V. Cherkashina, A.V. Kholod 
As an effective alternative an approach based on the application of the methods of computational intelligence and, above all, artificial neural networks and fuzzy inference systems can serve. The effectiveness of these systems is linked with their universal approximating capabilities and ability to learn directly in the prediction process.

Today, these techniques have proven their effectiveness in solving a wide range of problems associated with forecasting in the power industry [5-7].

Methods for forecasting the EN electricity load, whose architecture is based on a hybrid of neural elements with estimation accuracy block is largely allows to obtain results as close to the real data. However, taking into account the significant impact of environmental conditions (wind speed and direction, ambient temperature, etc.) on the OL capacity, there is a need in saturation of quantitative and ordinal variables of the hidden layer for a more reliable forecast of the $\mathrm{EN}$ permissible mode [7-9].

The OL parameters monitoring system will become a tool for measuring the temperature of the wire, which will, based on a retrospective analysis of the stored information on the OL parameters to predict the thermal resistance of the OL and as a result to carry out the calculation of the permissible load capacity in real time.

The goal of the paper is to form a neuro-fuzzy network based on temperature monitoring of overhead transmission line for the prediction of the electrical network modes.

Main materials of investigation. To predict the $\mathrm{OL}$ permissible load capacity the use of the architecture of neuro-fuzzy network taking into account the temperature monitoring of the OL is proposed.

The proposed neuro-fuzzy network has a four-layer architecture with direct transmission of information. To create a fully connected mesh network architecture based on hybrid neural elements with estimation accuracy block the following two stages of the procedure are carried out:

- at the first stage by the main network (without estimation accuracy block) is generated;

- at the second stage architecture and network parameters obtained during the first stage are fixed, and to it the estimation accuracy block is added, the inputs of which are all input, internal and output signals of the main network, and additional input signals (if necessary).

From the zero-th layer the information is supplied to the first hidden layer delay and fuzzification of the input signals. In this layer the history of the predicted signal is formed, as well as the membership function of factors that are given in different scales of measurement. From the output of this layer information in digital form is supplied to the second and third hidden layers, which are formed from the same type of elementary Rosenblatt neurons. The output layer is formed by a single neuron with nonlinear activation function, on the output of which the predicted signal is formed $[9,10]$.
Adding the accuracy estimation block significantly expands the operational capabilities of the network through the addition to point approximations estimations of their expected accuracy, which reduces the level of uncertainty in the process of further decision-making.

On the input of the first hidden layer the following information is fed:

- quantitative variables:

- the current value of the predicted signal $y(k)$ (here $k=0,1,2, \ldots, N$ have the meaning of the current discrete time, $N$ is the length of the sample);

- air temperature;

- ordinal variables:

- relative humidity in the form of «low - medium - high»;

- the wind speed in the form of «calm - weak strong - Hurricane»;

- cloudiness in the form of «clear - variable dense»;

- the number of hour of the day: $0,1,2, \ldots, 23$;

- day of the week in the form of «Monday Tuesday $-\ldots$ - Sunday»;

- nominal variables:

- the type of the day in the form of «working holiday - a holiday - a regional holiday - ported off - the transferred working»;

- the type of weather in the form of «rain - fog rain - snow».

Variables are precoded in the interval $[0,1]$ as follows:

$$
\begin{gathered}
\tilde{x}_{l}=\frac{\hat{x}_{l}-\hat{x}_{l \text { min }}}{\hat{x}_{l \text { max }}-\hat{x}_{l \text { min }}}, \\
\hat{x}_{l}=\hat{x}_{l \text { max }} \tilde{x}_{l}-\hat{x}_{l \text { min }}\left(\tilde{x}_{l}-1\right),
\end{gathered}
$$

where $\hat{x}_{l}$ is the value of the $i$-th input variable in the initial measurement scale: $\mathrm{MW} \cdot \mathrm{h},{ }^{\circ} \mathrm{C} ; \tilde{x}_{l}$ is the coded value of the $l$-th input variable; $\hat{x}_{l \text { min }}, \hat{x}_{l \text { max }}$ are the minimal and maximal values of the $l$-th input variable in the initial scale.

Further, in the first hidden layer by using the delay elements $z^{-1}$ the background predicted signal is formed as $y(k-1), y(k-2), y(k-24), y(k-48), y(k-168), y(k-336)$, which is fed to the second hidden layer as a $x_{1}(k), x_{2}(k)$, $x_{3}(k), x_{4}(k), x_{5}(k), x_{6}(k)$, and depending on the horizon of anticipation and other delay values different from the above can be used [8-10].

Later in the same layer fuzzification of the air temperature signals, number of the hour of a day, relative humidity, wind speed, cloud cover, and day of the week using the triangular membership functions uniformly distributed in the range $[0,1]$ which have the following form is made:

$$
\mu_{l 1}=\frac{c_{l 2}-\tilde{x}_{l}}{c_{l 2}}, \quad \tilde{x}_{l} \in\left[0, c_{l 2}\right],
$$




$$
\begin{gathered}
\mu_{l i}=\left\{\begin{array}{l}
\frac{\widetilde{x}_{l}-c_{l, i-1}}{c_{l i}-c_{l, i-1}}, \quad \tilde{x}_{l} \in\left[c_{l, i-1}, c_{l i}\right], \\
\frac{c_{l, i+1}-\widetilde{x}_{l}}{c_{l, i+1}-c_{l i}}, \quad \tilde{x}_{l} \in\left[c_{l i}, c_{l, i+1}\right], \\
i=2, \ldots, p_{l}-1,
\end{array}\right. \\
\mu_{p_{l} i}=\frac{\tilde{x}_{l}-c_{l, p_{l}-1}}{1-c_{l, p_{l}-1}}, \quad \tilde{x}_{l} \in\left[c_{l, p_{l}-1}, 1\right],
\end{gathered}
$$

where $c_{l i}$ is the placement of the centre of the $i$-th function of the $l$-th variable membership, $p_{l}$ is the number of functions of the $l$-th variable membership.

The architecture of the predictive neuro-fuzzy network taking into account the parameters of the OL wire is shown in Fig. 1.

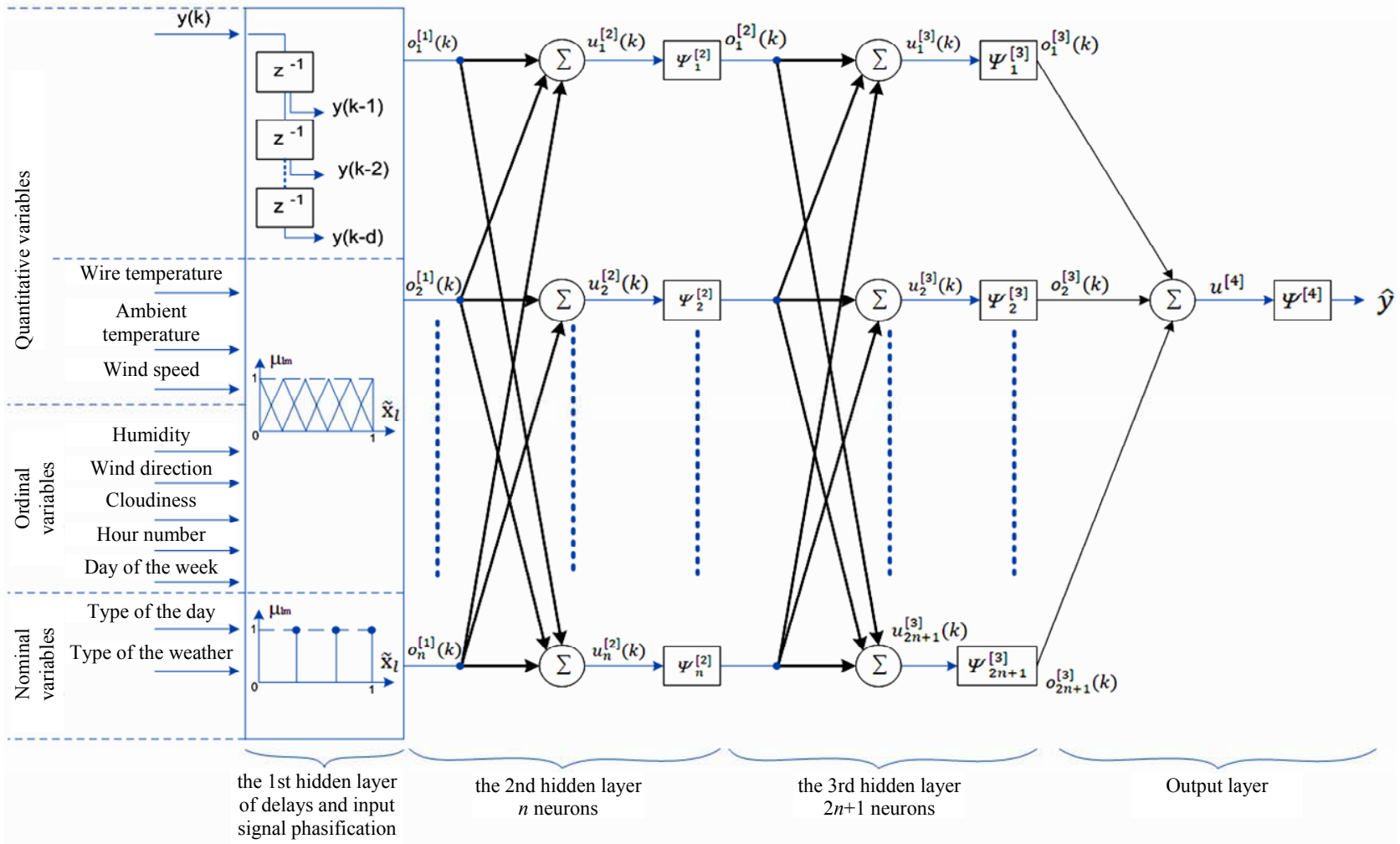

Fig. 1. Architecture of the predictive multilayer neuro-fuzzy network

As a result of processing of the original data in the first hidden layer a set of output signals $o_{1}{ }^{[1]}, o_{2}{ }^{[1]}, \ldots, o_{n}{ }^{[1]}$ is formed which are then fed to the second hidden layer in the form of the $(n+1) \times 1$-vector

$$
x^{[2]}=\left(1, o_{1}^{[1]}, o_{2}^{[1]}, \ldots, o_{n}^{[1]}\right)^{T},
$$

where the unit component needed to assess the displacement of each neurons of the subsequent layers.

The second hidden layer of the proposed neurofuzzy network has $n$ neurons of the same type with nonlinear sigmoidal activation functions $\psi_{j}^{[2]}, j=1,2, \ldots$, $n$ and contains $n(n+1)$ adjustable synaptic weights $w_{j i}^{[2]}$. The output of the $j$-th neuron of the second hidden layer has the form

$$
o_{j}^{[2]}=\psi_{j}^{[2]}\left(u_{j}^{[2]}\right)=\psi_{j}^{[2]}\left(\sum_{i=0}^{n} w_{j i}^{[2]} x_{i}^{[2]}\right),
$$

where $w_{j 0}^{[2]} \equiv \theta_{j}^{[2]}$ is the level of the $j$-th neuron displacement, and the output signal of the layer:

$$
o^{[2]}=\Psi^{[2]}\left(W^{[2]} x^{[2]}\right),
$$

where $o^{[2]}-(n \times 1)$ is the vector signal transmitted to the third hidden layer in the form $x^{[3]}=\left(1, o^{[2] T}\right)^{T}$, $\Psi^{[2]}=\operatorname{diag}\left\{\psi_{j}^{[2]}\right\}-(n \times n)$ is the matrix activation function, $W^{[2]}-n \times(n+1)$ is the adjustable matrix of synaptic weights.

The third hidden layer contains $2 n+1$ neurons and generates signals in the form

$$
\begin{gathered}
o_{j}^{[3]}=\psi_{j}^{[3]}\left(u_{j}^{[3]}\right)=\psi_{j}^{[3]}\left(\sum_{i=0}^{n} w_{j i}^{[3]} x_{i}^{[3]}\right), \\
o^{[3]}=\Psi^{[3]}\left(W^{[3]} x^{[3]}\right),
\end{gathered}
$$

where $\Psi^{[3]}=\operatorname{diag}\left\{\psi_{j}^{[3]}\right\}-((2 n+1) \times(2 n+1)$ is the matrix activation function, $W^{[3]}-((2 n+1) \times(n+1))$ is the matrix of adjustable synaptic weights, $o^{[3]}-((2 n+1) \times 1)$ is the vector signal transmitted to the output layer in the form

$$
x^{[4]}=\left(1, o^{[3] T}\right)^{T} .
$$


The output layer of the network is formed by a single neuron, forming a scalar signal of the forecast

$$
\hat{y}=\psi^{[4]}\left(u^{[4]}\right)=\psi^{[4]}\left(\sum_{i=0}^{2 n+1} w_{i}^{[4]} x_{i}^{[4]}\right)=\psi^{[4]}\left(w^{[4] T} x^{[4]}\right),
$$

where $w^{[4]}-((2 n+2) \times 1)$ is the vector of adjustable synaptic weights.

Combining expressions (9-11), the transfer function of the whole network has the form:

$$
\hat{y}=\psi^{[4]}\left(w^{[4] T} \Psi^{[3]}\left(W^{[3]} \Psi^{[2]}\left(W^{[2]} x^{[2]}\right)\right)\right) .
$$

The proposed in the paper approach provides high accuracy in forecasting at the conditions of the climate variability and stochastic input data for the prediction of the set of interrelated time series describing the consumption of electric energy within the several regions of the same territory which are included to the unified energy system.

Conclusions. The neuro-fuzzy network based on temperature monitoring of the overhead line is formed. A distinctive feature of the proposed network is the ability to process information specified in the different scales of measurement, and high performance for prediction modes of an electrical network.

\section{REFERENCES}

1. Naumov A.N., Vendrov A.M., Ivanov V.K. Sistemy upravleniia bazami dannykh $i$ znanii [Database management systems and knowledge]. Moscow, Finansy i statistika Publ., 1991. 352 p. (Rus).

2. Kenneth C. Sevcik. Priority scheduling disciplines in queueing network models of computer systems. In Proceedings of IFIP Congress'77. August 8-12, 1977, Toronto, Canada, pp. 565-570.

3. V. Mainkar, K.S. Trivedi. Approximate analysis of priority scheduling systems using stochastic reward nets. In Proceedings of the 13th International Conference on Distributed Computing Systems ICDCS'93. May 1993, Pittsburgh, PA, USA, pp. 466473. doi:10.1109/icdes.1993.287678.

4. Leonard Kleinrock. Queueing Systems. Volume 8: Computer Applications. John Wiley and Sons, New York, USA, 1976.

5. Popov S.V., Cheremisin M.M., Parkhomenko O.V., Shkuro K.A. Neural network method for predicting accidents due to formation of ice on power lines overhead. Visnyk Vinnytskoho politekhnichnoho instytutu - Visnyk of Vinnytsia Politechnical Institute, 2012, no.1, pp.161-163. (Ukr).
6. Popov S.V., Shkuro K.A., Cheremisin N.M., Parkhomenko O.V. A hybrid method of predicting ice load on power lines overhead. Enerhetyka ta elektryfikatsiia - Energetic and electrification, 2013, no.5, pp. 33-38. (Rus).

7. Kruglov V.V. Methods of forecasting multivariate time series. Pribory i sistemy. Upravlenie, kontrol', diagnostika Devices and systems. Management, monitoring, diagnostics, 2005, no.2, pp. 62-66. (Rus).

8. Popov S.V., Shkuro K.A. Evolutionary neuro-fuzzy network based on hybrid neural elements. 17 mizhn. konf. $z$ avtomatychnoho upravlinnia «Avtomatyka-2010». Tezy dopovidei [Proceedings of 17th Int. Conf. of Automatic Control «Automation 2010»]. Kharkiv (Ukraine), 2010, vol.2, pp. 193194. (Rus).

9. Popov S.V. Specialized architecture of artificial neural networks based on hybrid neural elements. Zbirnyk naukovykh prats Natsionalnoho hirnychoho universytetu - The collection of scientific works of National Mining University, 2009, vol.2, no.33, pp. 76-82.

10. Titov N.N. Povyshenie nadezhnosti $i$ kachestva funktsionirovaniia avtomatizirovannykh sistem dispetcherskogo upravleniia elektroenergeticheskimi sistemami [Improving the reliability and quality of the functioning of the automated systems of dispatching management of power systems]. Kharkov, Fakt Publ., 2013. 200 p. (Rus).

Received 20.10.2015

A.N. Moroz ${ }^{1}$, Doctor of Technical Science, Professor,

N.M. Cheremisin ${ }^{1}$, Candidate of Technical Science, Professor,

V.V. Cherkashina ${ }^{2}$, Candidate of Technical Science, Associate

Professor,

A.V. Kholod ${ }^{3}$, Engineer,

${ }^{1}$ Kharkiv Petro Vasylenko National Technical University

of Agriculture,

19, Engelsa Str., Kharkiv, 61052, Ukraine.

e-mail: moroz-fekt@inbox.ru, cheremisin.energy@rambler.ru

${ }^{2}$ National Technical University «Kharkiv Polytechnic Institute», 21, Frunze Str., Kharkiv, 61002, Ukraine.

e-mail: cherk34@rambler.ru

${ }^{3}$ Company «ELAKS»,

1, build. 12, Ac. Proskura Str., Kharkiv, 61085, Ukraine.

e-mail: underholod@mail.ru

\section{How to cite this article:}

Moroz A.N., Cheremisin N.M., Cherkashina V.V., Kholod A.V. Neural network modeling in problems of electrical grids modes prediction. Electrical engineering \& electromechanics, 2016, no.1, pp. 65-68. doi: 10.20998/2074272X.2016.1.12. 